\title{
TRENDS IN IMPROVING THE STRUCTURE OF A ROTARY DRYER
}

\author{
Edmund Kamiński ${ }^{\mathrm{a}^{*}}$, Viktor Evgenevič Kruglenja ${ }^{\mathrm{b}}$, Viktor Iofimovič Kocuba ${ }^{\mathrm{b}}$, \\ Maciej Kubońc, Vjačesłav Alekseevič Šaršunov ${ }^{d}$ \\ ${ }^{a}$ Institute of Technology and Life Sciences, Masovian Research Centre in Kludzienko \\ ${ }^{\mathrm{b}}$ Belorussian Agricultural Academy, Gorki, Mogilev Region, Belarus \\ ${ }^{\mathrm{c}}$ Institute of Agricultural Engineering and Informatics, University of Agriculture in Krakow \\ ${ }^{\mathrm{d}}$ Mogilev State University of Food Technologies, Belarus \\ *Corresponding author: e-mail: e.kaminski@itep.edu.pl
}

\begin{tabular}{|c|c|}
\hline ARTICLE INFO & ABSTRACT \\
\hline $\begin{array}{l}\text { Article history: } \\
\text { Received: March } 2015 \\
\text { Received in the revised form: } \\
\text { September } 2015 \\
\text { Accepted: November } 2015\end{array}$ & $\begin{array}{l}\text { The article presents rational principles for improving the structure of } \\
\text { a flax heap drier. As a result of tests which were carried out, we } \\
\text { established that the counter-flow rotary dryer SKM-1 is the most } \\
\text { perspective for drying flax heap. For effective drying of the flax heap } \\
\text { fine fraction the second rotating screen above the loaded layer of flax } \\
\text { heap is suggested in the SKM-1 dryer. Consequently, the drying agent } \\
\text { processed on the bottom screen is used for preliminary drying and } \\
\text { removal of surface moisture of the material loaded on the top screen. } \\
\text { For the purpose of maintaining the uniform drying of the material it is } \\
\text { recommended to carry out loosening and hashing during the drying } \\
\text { process with the help of the loosening device, established as the V- } \\
\text { shaped device on the discharge unit on the way to a mill. The prelimi- } \\
\text { nary heating of the flax heap on the top screen essentially accelerates } \\
\text { drying and allows the increase of the dryer performance and can } \\
\text { minimize energy requirement for drying. The correctly selected modes } \\
\text { of the drying process provide favorable conditions for ripening flax } \\
\text { seed, avoid damage of drying material and improve its sowing quality. }\end{array}$ \\
\hline
\end{tabular}

\section{Введение}

В технологической схеме послеуборочной обработки льновороха ответственным звеном является досушивание, так как от влажности зависят сохранность и качество семян. Вместе с тем эта операция одна из самых энергоемких. Затраты топлива на досушивание составляют около 90\% всех энергетических затрат при производстве семян.

Наиболее перспективными для досушивания льновороха являются карусельные сушилки. Продолжительность досушивания на них в 1,7-3,0 раза меньше, а энергия прорастания семян до $8 \%$ и полевая всхожесть до $17 \%$ выше по сравнению с досушиванием на напольных и конвейерных сушилках (Микяленис, Микшене 1991, Каминьски и др. 2014a; 2014б). Однако при досушивании предварительно отсепарированного льновороха нарушается непрерывность процесса, увеличивается 
E. Kamiński, V.E. Kruglenja, V.I. Kocuba, M. Kuboń, V.A. Šaršunov

продолжительность досушивания, растут энергозатраты. Таким образом, совершенствование сушильных установок, обоснование их рациональных параметров и режима работы с целью снижения энергозатрат является актуальной задачей, решение которой обеспечивает существенное повышение эффективности получения семенного материала льна.

Несмотря на то, что карусельные сушилки, наиболее перспективные для досушивания льновороха, они имеют ряд существенных недостатков. Низкая производительность отделения приема вынуждает разгружать ворох на площадки временного хранения, затем грузить его в транспортные средства и подавать в линию. В результате увеличиваются затраты труда, стоимость обработки, потери семян. Не совсем эффективна загрузка сушильной камеры транспортеромзагрузчиком. Неравномерность заполнения сушильной камеры достигает $45 \%$. В результате ворох пересушивается, увеличивается повреждение семян, снижается всхожесть. При толщине слоя вороха 0,4-0,6 м в нем наблюдается формирование каналов, сквозь которые агент сушки проходит, оказывая минимальное досушивающее воздействие на ворох. Увеличивается продолжительность досушивания, удельные затраты топлива и энергии (Шаршунов и др. 2005а; 2005б).

\section{Методика исследований}

В УО «БГСХА» разработана схема двухъярусной карусельной сушилки с рыхляще-перемешивающим устройством. Технологический процесс досушивания осуществляется следующим образом (рис. 1). Льноворох равномерно загружается транспортером-загрузчиком 1 на верхнюю решетчатую платформу 3, где снимается примерно 50\% влаги. Далее ворох перегружается на нижнюю платформу 4 при повернутом положении сегментов верхней платформы через образовавшийся зазор в верхней платформе, а на верхнюю платформу загружается новая партия сырого вороха в опущенном положении сегментов кольцевой сушильной камеры. В результате отработавший на нижней платформе сушильный агент $Q_{3}$ используется для предварительного подогрева вороха на верхней платформе. Ворох,загруженный на нижнюю платформу, досушивается до кондиционной влажности с рыхлением и перемешиванием и выгружается с помощью выгрузного устройства 10. После этого подсушенный ворох с верхней платформы 3 перегружается на нижнюю, далее процесс повторяется. Сушилка снабжена клапаном 8, который позволяет пропускать сушильный агент под нижнюю $-Q_{1}$ или под верхнюю $-Q_{2}$, а также комбинированно - под обе платформы одновременно. 
Trends in improving...

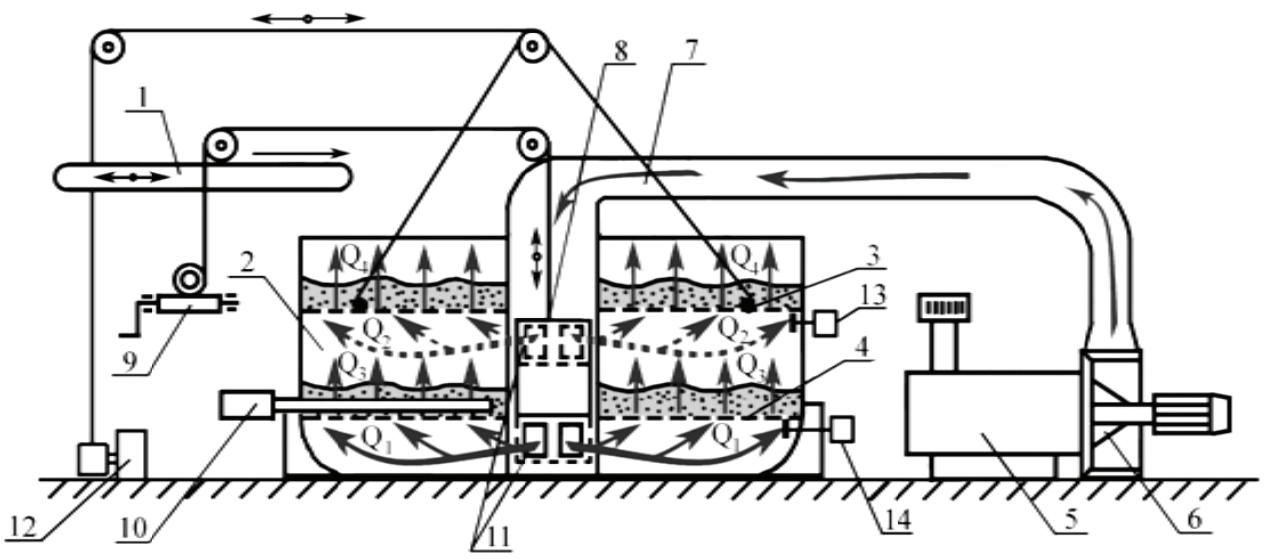

1 - транспортер-загрузчик, 2 - кольцевая сушильная камера, 3,4 - верхняяи нижняя решетчатые платформы, 5 - топочный агрегат, 6 - вентиляционный блок, 7 - воздуховод, 8 - распределительный клапан, 9, 12 - механизм подъёма и опускания распределительного клапана и верхней платформы, 10 - выгрузное устройство с рыхлителем, 11 - верхние и нижние окна ввоздуховоде, 13,14 - механизм привода верхней и нижней платформ

\section{Рисунок 1. Схема двухъярусной карусельной сушилки}

Применение усовершенствованной сушилки позволяет снизить энергозатраты при досушивании льновороха за счет равномерной загрузки, рыхления и перемешивания вороха и непрерывности двухстадийного технологического процесса сушки.

Теоретически рассмотрен процесс досушивания вороха льна с рыхлением и перемешиванием двухъярусной сушилкой. Получена математическая зависимость скорости движения рамы транспортера-загрузчика для равномерности загрузки сушилки; определена закономерность движения слоя льновороха по рабочей поверхности рыхляще-перемешивающего устройства; установлена взаимосвязь площади поверхности испарения досушиваемого материала и температуры нагревания льновороха, с которой начинается испарение; разработана система уравнений для описания процесса испарения влаги из льновороха. Получены уравнения позволяющие определить основные технологические параметры процесса досушивания и его продолжительность в зависимости от исходных показателей: влажности, температуры, высоты слоя, скорости движения агента сушки и температуры окружающей среды; получена дифференциальная форма уравнения Дальтона, определяющая скорость испарения влаги. Получена эмпирическая формула для расчета давления насыщенного пара в материале в зависимости от его влажности.

Равномерность загрузки сушильной платформы в значительной мере влияет на качество и продолжительность досушивания материала и зависит от скорости

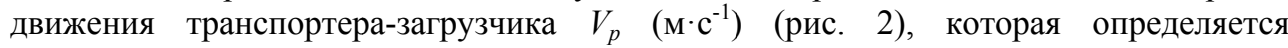
полученной формулой. 


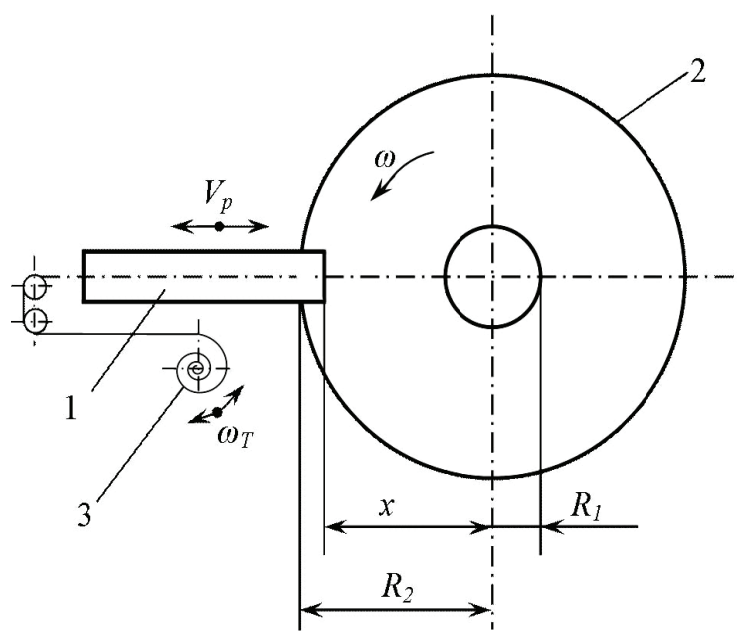

1 - транспортер-загрузчик; 2 - сушильная камера карусельной сушилки; 3 - спиральная намотка привода транспортера; $\mathrm{R}_{1}, \mathrm{R}_{2}$ - радиусы внутреннего и внешнего ограждения сушильной камеры, (м); $\mathrm{V}_{\mathrm{p}}$ - скорость движения транспортера- загрузчика, $\left(\mathrm{м}^{-1} \mathrm{c}^{-1}\right) ; \omega$ - угловая скорость решетчатой платформы, $\left(\mathrm{c}^{-1}\right) ; \omega_{\mathrm{T}}$ - угловая скорость вала привода транспортера-загрузчика, $\left(\mathrm{c}^{-1}\right)$

Рисунок 2. Схема для определения скорости движения транспортёра-загрузчика, подаюшего льноворох в сушильную камеру

$$
V_{P}=\frac{R_{2}^{2}-R_{1}^{2}}{2 \cdot T_{0} \cdot \sqrt{R_{1}^{2}+\frac{R_{2}^{2}-R_{1}^{2}}{T_{0}} \cdot \tau_{c}}},
$$

где:

$R_{1}, R_{2}$ - радиусы внутреннего и внешнего ограждения сушильной камеры, (м)

$T_{0} \quad-$ время движения транспортёра-загрузчика от внешнего к внутреннему ограждению, (c)

$\tau_{c} \quad$ - время сброса льновороха на платформу сушилки в точке $x,(\mathrm{c})$

Выражение (1) устанавливает закономерность движения транспортера-загрузчика для равномерной загрузки сушильной камеры при спиральной намотке троса его привода (рис. 3).

Теоретическими исследованиями обоснована скорость транспортера-загрузчика 0,03-0,1 м c $^{-1}$ обеспечивающая равномерность загрузки сушилки до $85 \%$.

На нижнем ярусе сушилки льноворох перемешивается рыхлящеперемешивающим устройством. Путь, пройденный ворохом по рабочей поверхности рыхлителя, должен быть не больше пути для предельного значения времени $\tau$, при котором скорость вороха равна нулю. При этих условиях движение вороха будет происходить непрерывно, без сгруживания перед рыхлителем. Исходя из этого при конструировании рыхлителя в виде наклонной плоскости его длину $l$ (м), угол 
Trends in improving...

наклона $\phi$ (град) и высоту сброса $H$ (м) (рис. 4), следует выбирать так, чтобы выполнялось неравенство (2).

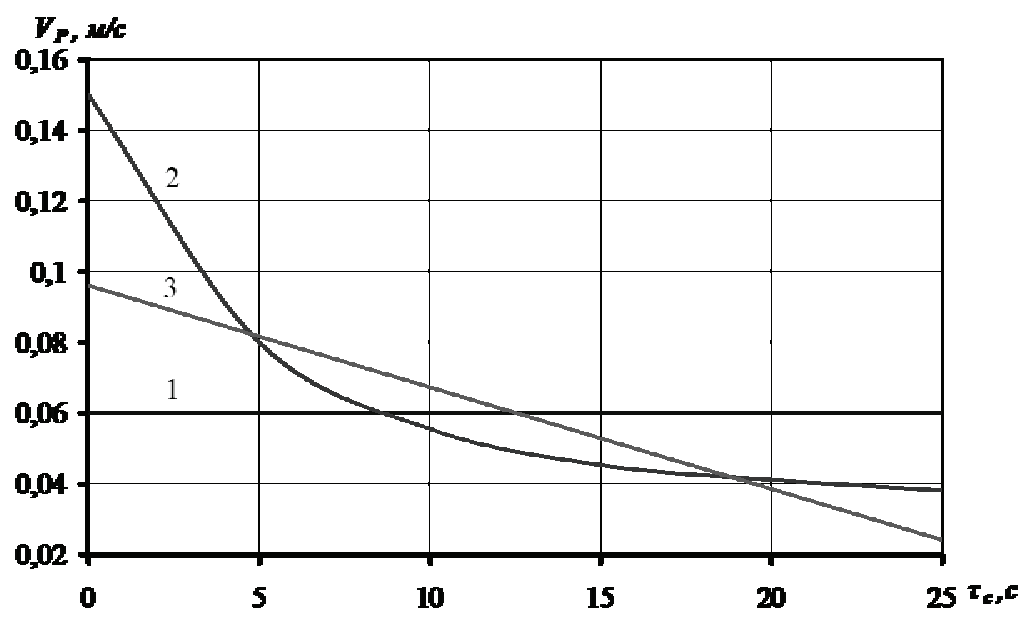

1 - равномерная скорость движения; 2 - рациональная скорость движения; 3 - скорость движения при спиральной намотке троса

Рисунок 3. Зависимость скорости движения транспортера-загрузчика от времени сброса вороха

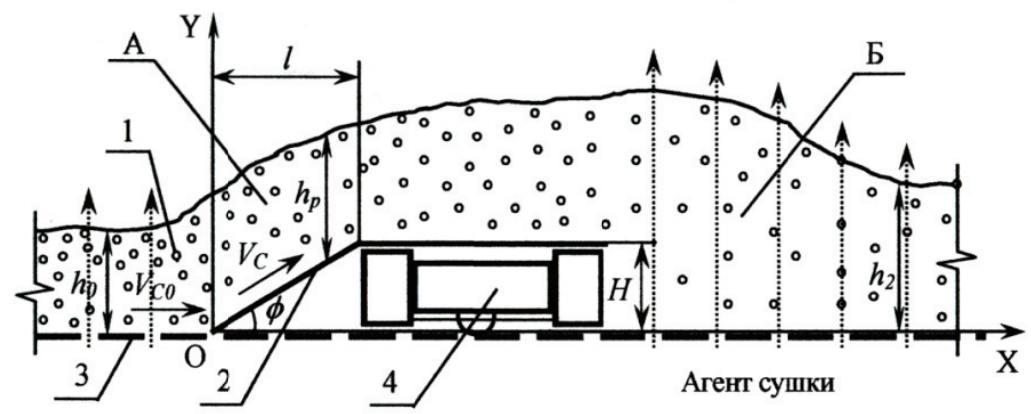

1 - слой льновороха; 2 - рыхлитель; 3 - решетчатая сушильная платформа; 4 - выгрузное устройство с рыхлителем; А - зона рыхления; Б - зона перемешивания материала нестесненным агентом сушки; $\phi$ - угол наклона рыхлящей поверхности; $h_{0}, h_{p}, h_{2}$ - высота слоя вороха перед рыхлителем, на рабочей поверхности рыхлителя и после перемешивания, (м); $H$ высота сброса льновороха, (м); $V_{C 0}$ - скорость движения вороха до встречи с рыхлителем, (м*c $\left.{ }^{1}\right) ; V_{C}-$ скорость движения вороха на рабочей поверхности рыхлителя, $\left(\right.$ м $\left.\cdot \mathrm{c}^{-1}\right)$

Рисунок 4. Схема прохождения слоя льновороха по рабочей поверхности рыхлящеперемешивающего устройства 


$$
\phi \geq \arccos \sqrt{\frac{(H-\ell \cdot(2 \cdot \pi \cdot R \cdot \eta-f)) \cdot 2 \cdot g}{\omega^{2} \cdot R^{2}}},
$$

где:

$R \quad$ - текущее значение радиуса сушильной камеры, (м)

$\eta$ - коэффициент пропорциональности, учитывающий наличие внутреннего трения вороха на единицу длины

$f \quad-$ коэффициент трения вороха о сталь

$\omega-$ частота вращения платформы, $\left(\right.$ мин $\left.^{-1}\right)$

$g \quad-$ ускорение свободного падения, $\left(\mathrm{M} / \mathrm{c}^{-2}\right)$

Угол наклона рыхляще-перемешивающей поверхности, при котором не происходит сгруживание льновороха, находится в пределах 37,5-43,5 град.

\section{Результаты исследований}

В процессе нагревания льновороха и испарения влаги одним из основных показателей, влияющих на интенсивность досушивания, является площадь поверхности испарения $S_{M}\left(\mathrm{M}^{2}\right)$, которая характеризуется размерными характеристиками компонентов вороха (радиусом коробочек льна $R_{K}\left(\right.$ м) и стеблей $R_{C}$ $(\mathrm{M})$, а также их длиной $\left.l_{C}(\mathrm{M})\right)$. Получено уравнение для расчета площади поверхности испарения в виде (Шаршунов и др. 2005в)

$$
S_{M}=\frac{V_{M}}{100} \cdot\left(\frac{3 \cdot Q_{K}}{R_{K}}+\frac{2 \cdot Q_{C}}{R_{C}}+\frac{2 \cdot Q_{C}}{\ell_{C}}\right),
$$

где:

$V_{M} \quad$ - объем досушиваемого вороха, $\left(\mathrm{м}^{3}\right)$

$Q_{K}, Q_{C}$ - процентное отношение объема коробочек $V_{K}$ и стеблей $V_{C}$ к объему вороха $V_{M}$.

Графическая зависимость площади поверхности испарения $S_{M}$ от размерных характеристик компонентов льновороха представлена на рис. 5.

Площадь поверхности испарения находится в пределах 1500-3200 м².

Также получена эмпирическая формула поправочного коэффициента для расчета давления насыщенного пара в льноворохе в зависимости от его влажности:

$$
K=1-e^{-\cdot-\mathrm{z} W_{\mathrm{A}}},
$$

где:

$W_{A}-$ текущее значение абсолютной влажности, $\left(\kappa \Gamma^{*} \kappa \Gamma^{-1}\right)$

$z$ - эмпирический коэффициент. 
Trends in improving...

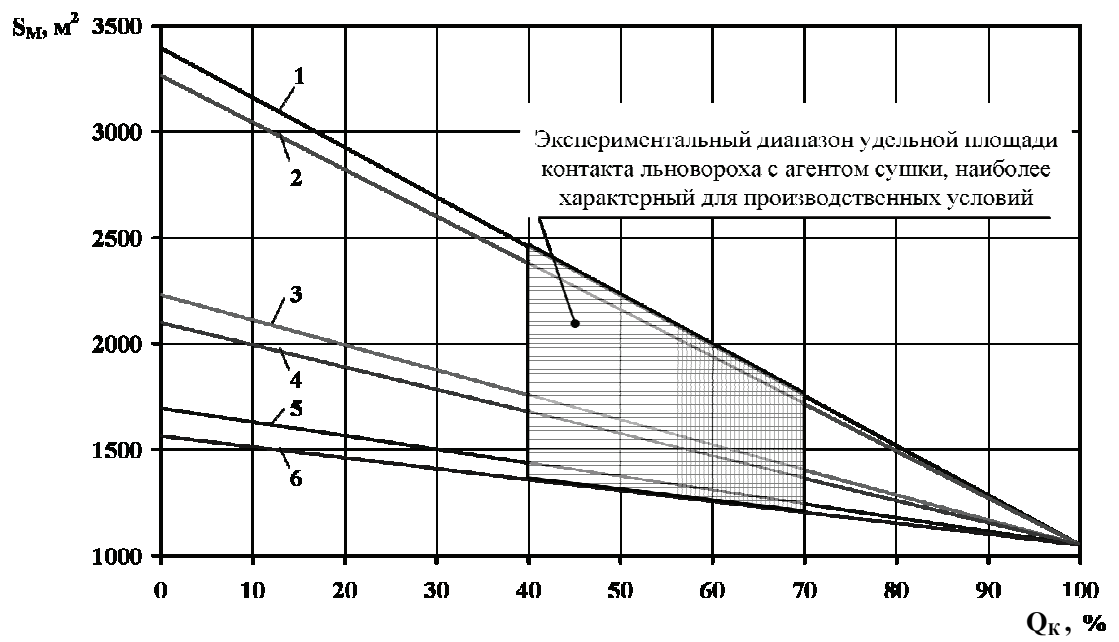

$1-R_{C}=0,00043 \mathrm{~m}, l_{C}=0,01 \mathrm{~m} ; 2-R_{C}=0,00043 \mathrm{~m}, l_{C}=0,15 \mathrm{~m} ;$

$3-R_{C}=0,00067 \mathrm{M}, l_{C}=0,01 \mathrm{~m} ; 4-R_{C}=0,00067 \mathrm{~m}, l_{C}=0,15 \mathrm{~m} ; 5-R_{C}=0,0009 \mathrm{M}$, $l_{C}=0,01 \mathrm{~m} ; 6-R_{C}=0,0009 \mathrm{~m}, l_{C}=0,15 \mathrm{~m}$

Рисунок 5. Удельная площуадь контакта льновороха с агентом сушки в зависимости от состава вороха

Коэффициент $K$ для льновороха с абсолютной влажностью от 30 до $65 \%$ находится в пределах 0,699-0,926.

Сушественное влияние на время досушивания оказывает температура нагревания льновороха, с которой начинается процесс испарения влаги $\theta_{H}$. Получена зависимость определения $\theta_{H}$ в виде

$$
\theta_{H}=t-18,67 \ln \frac{1-e^{-\mathrm{z} \cdot W_{A O}}}{\varphi},
$$

где:

$\varphi$ - относительная влажность воздуха, в долях.

Её величина зависит от абсолютной влажности вороха в начальный момент досушивания $W_{A O}\left(\kappa \Gamma^{\circ} \kappa^{-1}\right)$ и температуры агента сушки $t\left({ }^{\circ} \mathrm{C}\right)$.

Графически зависимость температуры начала испарения от влажности воздуха при различной начальной влажности материала представлена на рис. 6 . 


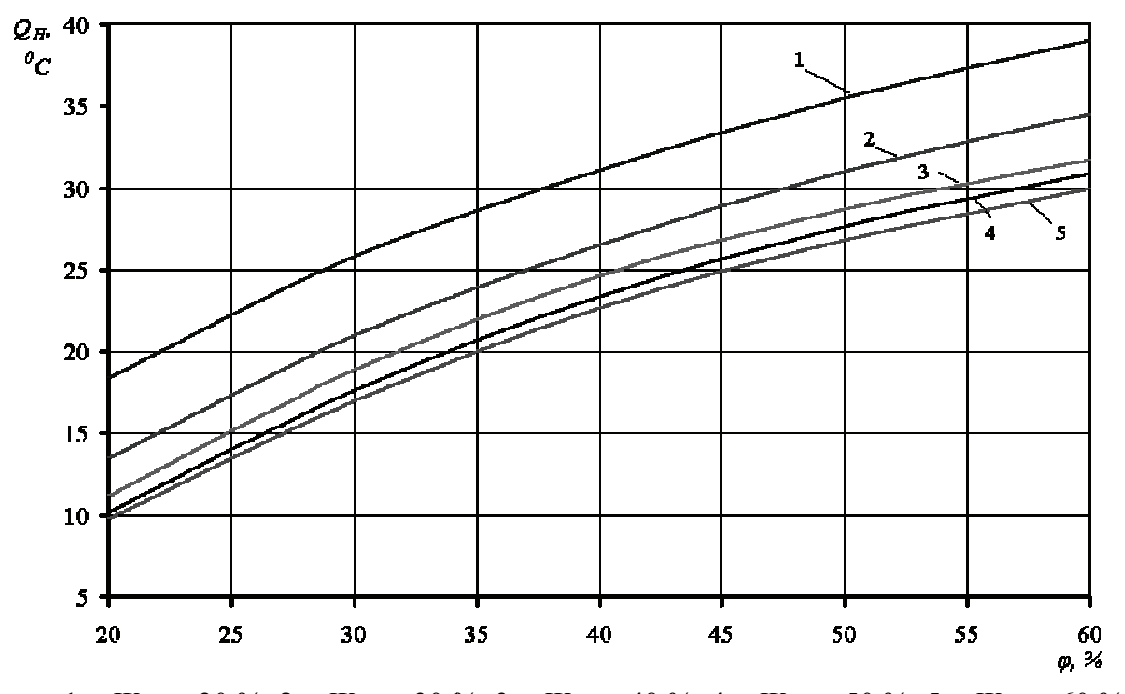

$1-W_{A O}=20 \% ; 2-W_{A O}=30 \% ; 3-W_{A O}=40 \% ; 4-W_{A O}=50 \% ; 5-W_{A O}=60 \%$

Рисунок 6. Зависимость температуры начала испарения от влажности воздуха при различной начальной влажности льновороха

На основании закона Дальтона получено дифференциальное уравнение, позволяющее определить скорость испарения влаги из льновороха в зависимости от его структуры, чтов свою очередь, позволяет установить время перегрузки вороха с верхней на нижнюю сушильную платформу:

$$
d W_{A}=-81.68 \cdot \beta_{P} \cdot S_{M} \cdot G_{C}\left(K \cdot e^{m \cdot \theta}-\varphi \cdot e^{m \cdot t}\right) \cdot d \tau
$$

где:

$$
\begin{aligned}
& \beta_{P}-\text { коэффициент влагообмена, }\left(1 \cdot \mathrm{ч}^{-1}\right) \\
& G_{C}-\text { вес сухого материала, (кг) } \\
& m-\text { эмпирический коэффициент, }\left(1 /{ }^{\circ} \mathrm{C}\right) \\
& \theta-\text { температура материала в процессе досушивания, }\left({ }^{\circ} \mathrm{C}\right) \\
& \tau-\text { время досушивания, }(\text { ч). }
\end{aligned}
$$

Температура семян в процессе досушивания имеет решающее значение для сохранения посевных кондиций семян. Она же определяет периодичность подачи подогретого и неподогретого воздуха в процессе досушивания. Для её определения получена зависимость

$$
\mathrm{S}_{\mathrm{M}} \cdot \alpha \cdot(\mathrm{t}-\theta) \cdot \mathrm{d} \tau=(595+0,47 \cdot \mathrm{t}) \cdot \mathrm{dW}_{\mathrm{A}}-\theta \cdot \mathrm{dWA}+\left(\mathrm{C}_{\mathrm{C}} \cdot \mathrm{G}_{\mathrm{C}}+\mathrm{W}_{\mathrm{A}}\right) \cdot \mathrm{d} \theta
$$
где:

$\alpha-$ коэффициент теплоотдачи от воздуха к материалу, $\left(\right.$ ккал $\left.\cdot \mathrm{M}^{-2} \cdot \mathrm{\varphi} \cdot{ }^{\circ} \mathrm{C}\right)$

$C_{C} \quad$ - теплоемкость сухого материала, (ккал· кг $\left.{ }^{-1}{ }^{\circ} \mathrm{C}\right)$. 
Trends in improving...

Предполагая, что $\mathrm{t}$ - const по всему слою и решая совместно уравнения (6) и (7), можно определить температуру льновороха и его влажность в любой момент времени досушивания $\tau$.

Получена зависимость, описывающая процесс досушивания льновороха в зависимости от температуры агента сушки, исходной влажности вороха, начальной температуры испарения и влажности воздуха

$$
W_{A}=\frac{1}{z} \cdot \ln \left(\left(e^{z \cdot W_{A O}}-\frac{e^{m \cdot \theta_{H}}}{e^{m \cdot \theta_{H}}-\varphi \cdot e^{m \cdot \theta_{H}}}\right) \cdot e^{-a \cdot \tau}+\frac{e^{m \cdot \theta_{H}}}{e^{m \cdot \theta_{H}}-\varphi \cdot e^{m \cdot \theta_{H}}}\right),
$$

где:

$$
a-\text { эмпирический коэффициент, }\left(1 \cdot ч^{-1}\right)
$$

На рис. 7 построены кривые досушивания, полученные по формуле (8) при различных значениях влажности воздуха $\varphi$ и начальной абсолютной влажности материала $W_{A O}$. Там же отложены значения абсолютной влажности $W_{A}$ по опытным данным.

Предлагаемая модель анализа процесса досушивания является базой для дальнейшей разработки аналитических методов изучения процесса досушивания и выбора оптимальных режимов работы усовершенствованной сушилки. Поэтому ее использование является перспективным при решении подобных задач.

Для получения математических моделей процессов досушивания и рыхления с перемешиванием льновороха проведен выбор и обоснование интервалов варьирования основных факторов, оказывающих наиболее существенное влияние на параметры оптимизации процессов досушивания и рыхления с перемешиванием. Интервалы варьирования факторов и границы варьирования были определены на основании проведенных теоретических исследований и априорной информации. В результате поисковых экспериментов были установлены рациональные интервалы варьирования факторов: начальная влажность льновороха $W_{A O}-30-45 \%$; содержание в ворохе посторонних примесей $\mu-10-31 \%$; толщина слоя вороха $h-0,40-0,50$ м; скорость движения агента сушки $V-0,22-0,3 \mathrm{~m} \cdot \mathrm{c}^{-1}$; температура агента сушки $t-36-$ $40^{\circ} \mathrm{C}$; периодичность перемешивания вороха $t_{\Pi}-1,5-2,5$ ч. За функцию отклика $\tau$ было принято время досушивания льновороха до кондиционной влажности.

После проведения отсеивающих экспериментов установлено, что факторами, оказывающими наиболее существенное влияние на параметр оптимизации процесса досушивания, являются: толщина слоя вороха, периодичность перемешивания и температура агента сушки. В результате проведения дальнейших исследований получена математическая модель процесса досушивания (Кругленя, и др. 2008):

$$
\begin{gathered}
\tau_{1}=10,300+1,129 \cdot h+0,696 \cdot t_{I I}-0,558 \cdot t+0,100 \cdot h \cdot t_{I I}-0,042 \cdot h \cdot t- \\
-0,058 \cdot t_{I I} \cdot t-0,008 \cdot h^{2}+0,075 \cdot t_{I I}^{2}+0,017 \cdot t^{2} .
\end{gathered}
$$

Область оптимума исследуемых факторов находится в следующих пределах: толщина слоя льновороха - 0,40-0,50 м; периодичность перемешивания вороха - 1,01,5 ч; температура агента сушки $-38-40^{\circ} \mathrm{C}$. (Кругленя, и др., 2007). 


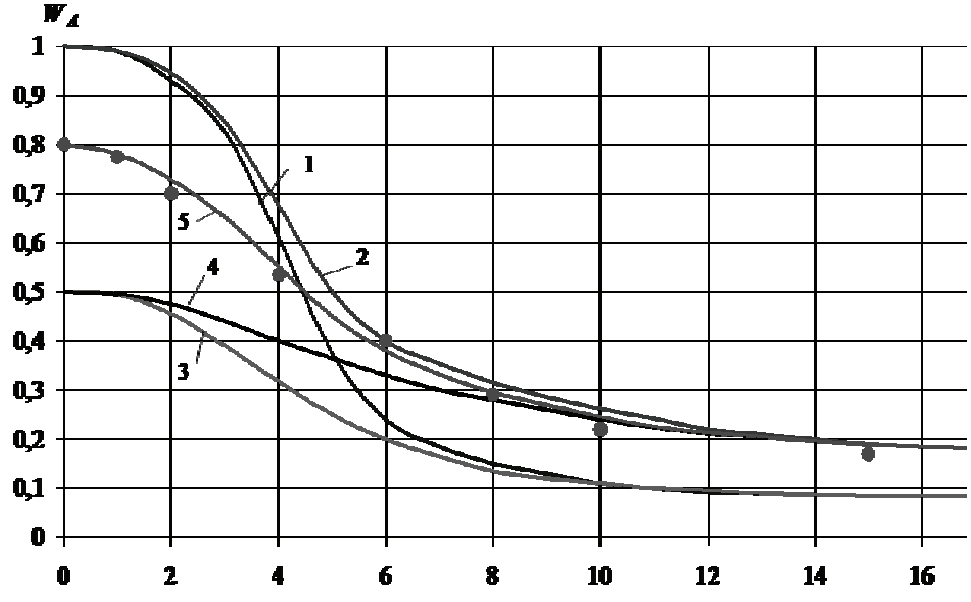

$W_{A O}: 1-W_{A O}=1, \varphi=0,2 ; 2-W_{A O}=1, \varphi=0,5 ; 3-W_{A O}=0,5 ; \varphi=0,2 ; 4-W_{A O}=0,5, \varphi=0,5$; $5-W_{A O}=0,8, \varphi=0,5$ (сравнение с экспериментом)

Рисунок 7. Кривые досушивания при различных значениях влажности воздуха и начальной абсолютной влажности льновороха

Во время производственных испытаний определялись зависимости времени досушивания, удельного расхода электроэнергии и топлива от начальной влажности материала, высоты слоя, скорости движения агента сушки и периодичности перемешивания вороха (рис. 8).

Для обеспечения непрерывности работы сушилки разработан график, в котором согласованы технологические операции загрузки, досушивания, охлаждения, перегрузки, рыхления с перемешиванием и выгрузки льновороха. В процессе загрузки, перегрузки и выгрузки ворох продувается холодным и подогретым агентом сушки, как это представлено на рис. 9.

Для выбора рациональных значений технологического процесса досушивания нами предлагается номограмма (рис. 10).

Зная начальную влажность и выбрав температуру и скорость агента сушки с учетом периодичности перемешивания материала, находим толщину слоя и время досушивания.

Применение разработанного графика согласования технологических операций загрузки, досушивания, охлаждения, перегрузки, периодичности рыхления c перемешиванием снижает энергозатраты при досушивании на 40-60\%, а разработанная номограмма позволяет определить время досушивания и режимы работы сушилки в зависимости от исходной влажности льновороха с учетом периодичности рыхления с перемешиванием. 


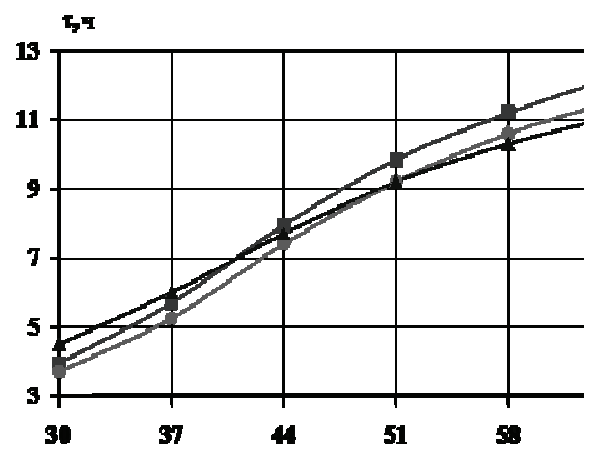

a)

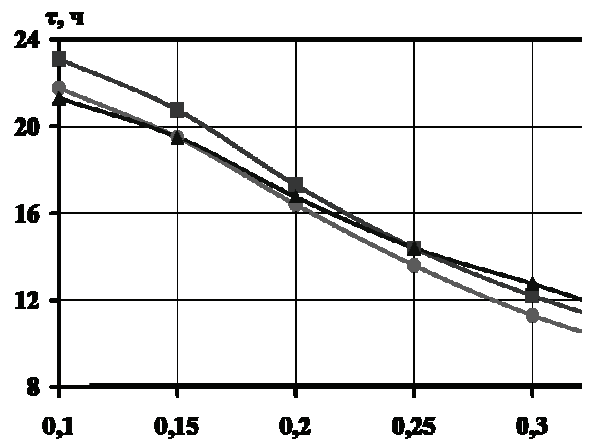

B)

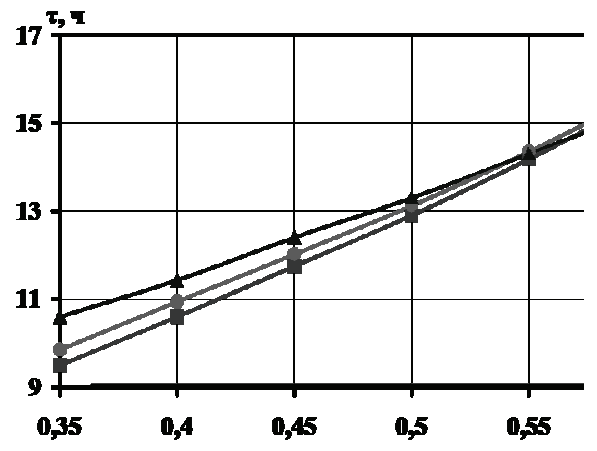

б)

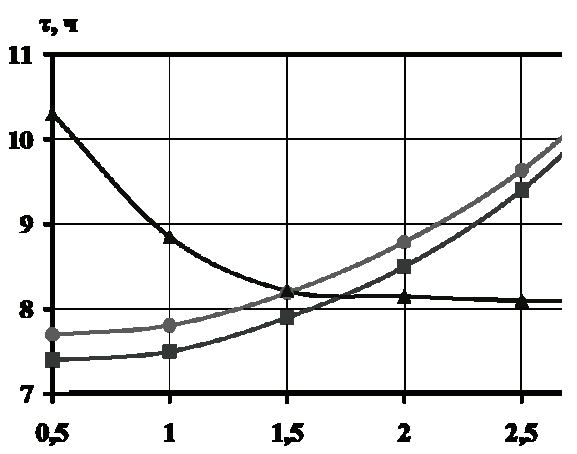

г)

$\longrightarrow$ время досушивания, $\tau$, ч; —- удельный расход топлива, $Q_{m}, \kappa^{\prime} \mathrm{T}^{-1}$; $\longrightarrow$ - удельный расход электроэнергии, $Q_{э л}$, кВт·(ч· $\left.{ }^{-1}\right)$

Рисунок 8. Показатели работы сушилки в зависимости от начальной влажности (a), выссоты слоя (б) вороха, скорости агента сушки (в) и периодичности перемешивания (2) 
E. Kamiński, V.E. Kruglenja, V.I. Kocuba, M. Kuboń, V.A. Šaršunov

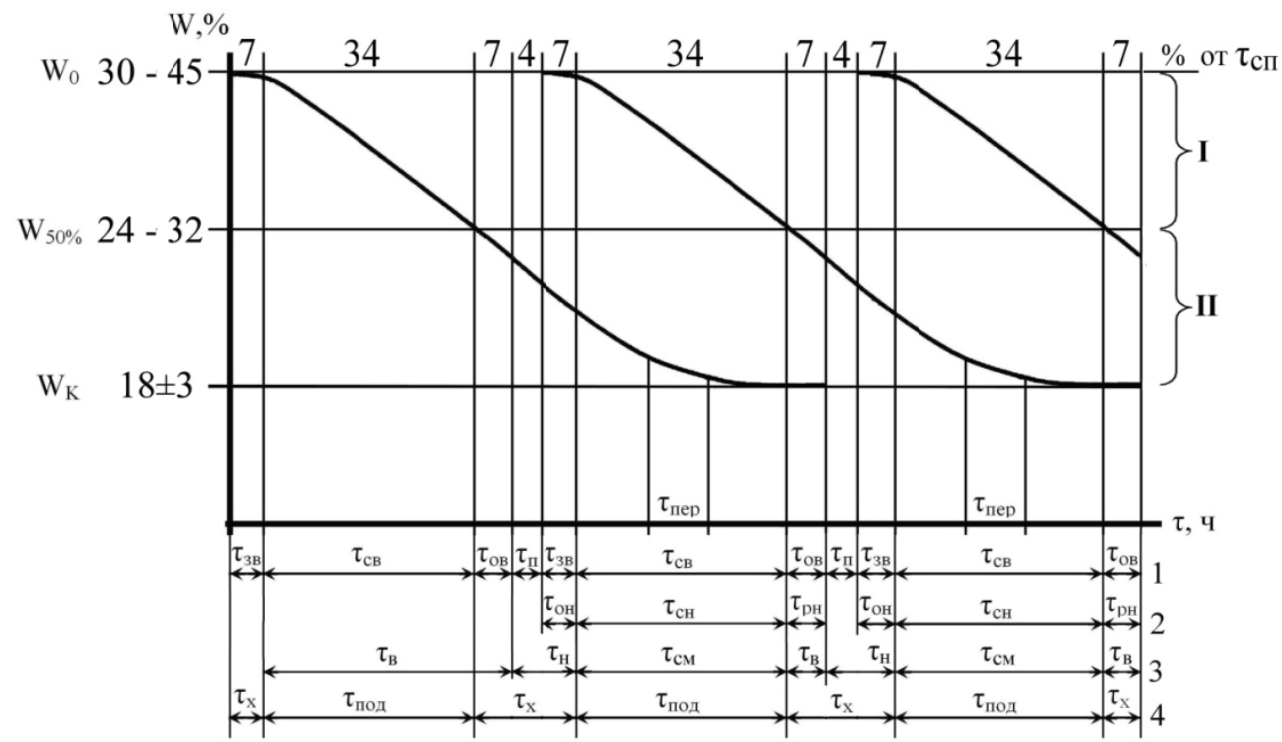

Рисунок 9. График согласования работы двухъярусной карусельной сушилки

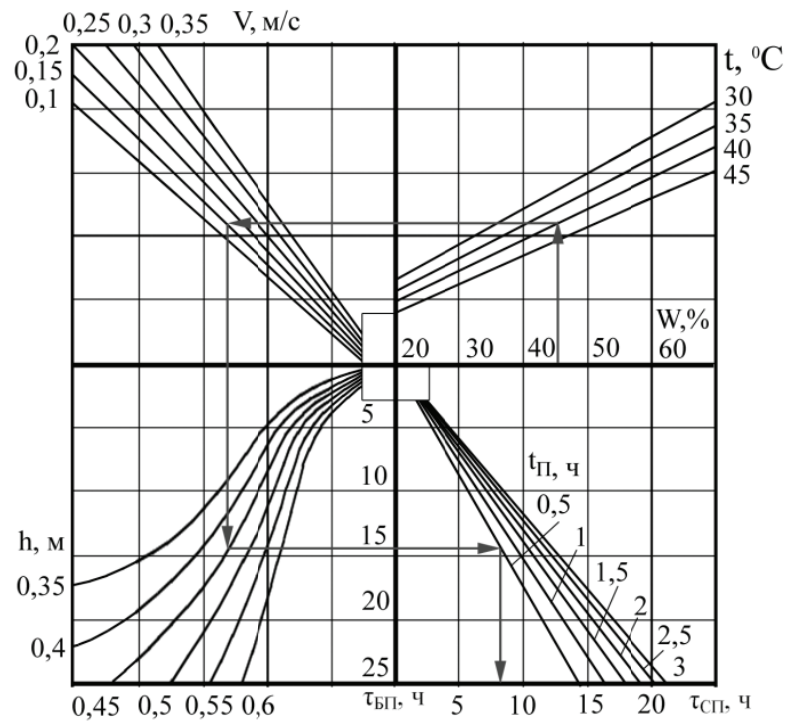

$W$ - начальная влажность льновороха, (\%); $t$ - температура, $\left({ }^{\circ} \mathrm{C}\right) ; V$ - скорость агента сушки, $\left(\mathrm{м}^{\cdot} \mathrm{c}^{-1}\right) ; h$ - толщина слоя, (м); $t_{\Pi}-$ периодичность перемешивания, (ч); $\tau_{Б \Pi}-$ время досушивания без перемешивания, (ч); $\tau_{C \Pi}$ - время досушивания с перемешиванием, (ч)

Рисунок 10. Номограмма для выбора режима и определения продолжительности досушивания льновороха двухъярусной карусельной сушилкой с перемешиванием 
Trends in improving...

\section{Выводы}

В сравнении с серийной сушилкой двухстадийное досушивание льновороха с рыхлением и перемешиванием позволяет сократить время досушивания на 15-20\% на двухъярусной сушилке, увеличить производительность на 40-50\%, снизить энергозатраты в 1,6 раза.

Годовой экономический эффект от внедрения модернизированной сушилки составляет 21,6 евро на 1 тонну переработанного вороха.

\section{Литература}

Kamiński, E., Śarśunov, V.A., Kruglenja, V. E. (2014a). Physico-mechanical and technological characteristics of flax threshed mass and its components. Problemy Inżynierii Rolniczej, 2(84), 63-75.

Kamiński, E., Sarsunov, V. A., Kruglenja, V. E. (2014b). Pretreatment of flax threshed mass grown for seed. Problemy Inżynierii Rolniczej, 2(84), 77-86.

Кругленя, В.Е., Алексеенко, А.С., Кудрявцев, А.Н., Коцуба, В.И. (2006). Результаты исследований и эффективность применения двухьярусной противоточной карусельной сушилки. Вестник Белорусской государственной сельскохозяйственной академии, 4, 89-92.

Кругленя, В.Е., Алексеенко, А.С., Кудрявцев, А.Н., Коцуба, В.И. (2007). Уравнения для описания процесса испарения влаги из льновороха при досушивании. Вестник Белорусской государственной сельскохозяйственной академии, 1, 122-125.

Кругленя, В.Е., Алексеенко, А.С., Коцуба, В.И., Курзенков, С.В. (2008). Обоснование конструктивных параметров рыхлителя вороха карусельной сушилки. Вестник Белорусской государственной сельскохозяйственной академии, 2, 110-113.

Микяленис, С., Микшене, Г. (1991). Зависимость качества семенного материала льна от типа сушки. Сборник научных трудов. Литовской институт земеделия. Вильнюс. Bыnycк 68 , Агрономия, 104-107.

Šaršunov, V.A., Kruglenja, V.E., Kamiński, E., Kuboń, M. (2014). Flax seed separation with vibrating screens. Inżynieria Rolnicza, 3(151), 187-201.

Шаршунов, В.А., Кругленя, В.Е., Алексеенко, А.С., Кудрявцев, А.Н., Коцуба, В.И. (2005а). Рыхлитель-разравниватель льновороха для протвоточной карусельной сушилки. Мateriały Międzynarodowej Konferencji „Ekologiczne aspekty mechanizacji produkcji roślinnej” IBMER Warszawa 13-14 września 2005r., 202-206.

Шаршунов, В.А., Кругленя, В.Е., Алексеенко, А.С., Кудрявцев, А.Н., Коцуба, В.И. (2005б). Выбор режима работь двухьярусной карусельной сушилки. Materiały Międzynarodowej Konferencji „Ekologiczne aspekty mechanizacji produkcji roślinnej” IBMER Warszawa 13-14 września 2005 r., 163-168.

Шаршунов, В.А., Кругленя, В.Е., Алексеенко, А.С., Кудрявцев, А.Н., Коцуба, В.И. (2005в) Исследование процесса сушки льновороха двухьярусной карусельной сушилки. Вестник Национальной академии наук Беларуси. Серия аграрных наук, 4, 110-113.

Сорочинский, В. Ф. (2003). Послеуборочная обработка и хранение зерна. Механизация и электрификация сельского хозяйства, 1, 10-14. 
E. Kamiński, V.E. Kruglenja, V.I. Kocuba, M. Kuboń, V.A. Šaršunov

\section{KIERUNKI DOSKONALENIA KONSTRUKCJI SUSZARNI KARUZELOWEJ SKM-1}

Streszczenie. W artykule zamieszczono racjonalne zasady doskonalenia konstrukcji suszarni do suszenia lnianej masy omłotowej. W rezultacie przeprowadzonych badań ustalono, że najbardziej perspektywiczną, z punktu widzenia suszenia lnianej masy omłotowej, jest suszarnia karuzelowa SKM-1. Celem poprawy efektywności suszenia drobnej frakcji lnianej masy omłotowej proponuje się w suszarni SKM-1 montaż drugiego obrotowego kosza sitowego nad dotychczasowym (powyżej zasypywanej warstwy masy lnianej). W rezultacie czego przepracowany na dolnym sicie czynnik suszący wykorzystywany jest do wstępnego podgrzewania i usuwania wilgoci powierzchniowej, zasypywanego na górny kosz sitowy materiału. W celu zapewnienia równomiernego suszenia materiału zaleca się jego spulchnianie i mieszanie w procesie suszenia za pomocą spulchniacza wyrównywacza, ustawionego w postaci klinowej osłony na elemencie wyładowczym. Wstępne podgrzewanie lnianej masy omłotowej na górnym koszu sitowym istotnie przyspiesza jej dosuszanie, pozwala zwiększyć wydajność suszenia i ograniczyć nakłady energetyczne na dosuszanie. Prawidłowo dobrane parametry suszenia zapewniają dobre warunki dosuszania nasion lnu, ograniczając ich uszkadzanie, zwiększając ich właściwości siewne.

Słowa kluczowe: suszenie lnu, suszarnia karuzelowa, jakość suszenia 